\title{
Modelling Stakeholder Dynamics for Supporting Group Decision and Negotiation: Theory to Practice
}

\author{
Colin Eden $^{1}$ (D) Fran Ackermann ${ }^{2}$ (D)
}

Accepted: 4 May 2021 / Published online: 28 May 2021

(c) The Author(s) 2021

\begin{abstract}
Group Decision and Negotiation methods can help identify optimal, or efficient, solutions to complex problems and so aid decision-makers. However, recommendations depend for their success, in part, on their political feasibility within, usually, complex organisational settings. A part of the complexity of effective implementation derives from understanding the responses of stakeholders to the proposed decisions. The responses of stakeholders can be complex because stakeholders respond not just to the decision but also to the responses of other stakeholders. When the recommendations are very important, and when the possible stakeholder responses are likely to be complex, then the use of some form of modelling of stakeholder dynamics is likely to be helpful. This paper proposes such a modelling process designed to aid the thinking of a decision-making team as they seek to ensure their decision is politically feasible. The modelling process is designed to facilitate effective negotiation in groups about the potential impact of stakeholder responses. The modelling process is illustrated through a real case.
\end{abstract}

Keywords Stakeholder management $\cdot$ Systems thinking $\cdot$ Negotiating political feasibility

\section{Introduction}

Stakeholder management is critical to the successful implementation of strategic and operational decisions. In 1984 Freeman's book arguing for attention to stakeholders when developing strategy was the first significant body of work published

Colin Eden

colin.eden@strath.ac.uk

Fran Ackermann

fran.ackermann@curtin.edu.au

1 Department of Management Science, Strathclyde Business School, Glasgow G4 0GE, UK

2 School of Management and Marketing, Faculty of Business and Law, Curtin University, Perth GPO Box U1987, Western Australia 
in the field (Freeman 1984, republished in 2010). Since then the GDN literature has not provided analysis methods for the analysis of stakeholder dynamics (Eden et al. 2019). Stakeholder management is always context sensitive - for example 'political, social and technological contexts must also be reckoned with if the firm is to incorporate the range of situates and actors - both public and private-that affect its operations' (Cummings and Doh, 2000 p83). It is also important to recognise that "identification of both stakeholders and the interconnections between them is a critical step" (Freeman and McVea, 2001, p193).

Furthermore, approaches to refining the decisions, in both the public and private sectors, involve an explicit analysis of stakeholders and their aspirations, needs, and wants (Bryson et al. 2002; Eden and Ackermann 1998). Stakeholders matter immensely to the process of analysing and creating organizational strategy (Bryson 2004). Our own experience of working with management teams suggests that i) consideration of stakeholders is regarded as important by management teams as they develop strategy or identify solutions to complex and messy problems, and ii) they are helped in doing this through the use of modelling that can act as a boundary object (Black and Andersen 2012; Carlile 2002; Franco 2013; Quick and Feldman 2014) and transition object (Eden and Ackermann 2018; Ackermann and Eden 2010a; Ackermann and Eden 2011a, b; Ackermann et al. 2016; de Geus 1988; Eden and Ackermann 2004; Winnicott 1953). The modelling process is seen as enabling them to feel more confident about their strategy being closer to optimal as well as enhancing their own understanding of the stakeholder landscape. However, these modelling processes do not consider the dynamics of stakeholder responses. In this paper we present a modelling approach that supports managers in their consideration of the dynamics of stakeholder responses when refining decisions that follow from group decision and negotiation.

The purpose of this paper is twofold: i) to describe in detail a tried and tested modelling approach that can be used to help decision-makers recognise the dynamics of stakeholder responses when choosing how to respond to complex, multi-stakeholder, problems, and ii) to contribute to the development of a theory of stakeholder interactions that can be operationalised and thus extend research in strategic management, group decision and negotiation and stakeholder theory arenas.

As noted above, until now there has been little research undertaken that explores how a potential action of a stakeholder can be considered both in terms of its impact on the effectiveness of the decision through a consideration of its impact on other stakeholders and their resultant responses - taking a dynamic view. Some work within the Game Theory/Drama Theory arena (Berardo and Lubell 2016; Bryant 2016; Lubell 2013; Park and Rethemeyer 2014; Elsaid et al. 2017) makes a contribution, but the analysis process can be lengthy and relatively inaccessible to managers.

Although some publications have identified methods for stakeholder analysis (Ackermann and Eden 2011a, 2011b; Bryson 2018) these have not provided ways of analysing or modelling the dynamics of interactions between stakeholders. These dynamics may lead to a decision failing because the interactions between stakeholders triggered by the policy result in dysfunctional behaviour, or alternatively, if managed effectively, the interactions may lead stakeholders to behave in ways that reinforce the optimal delivery of the strategy. Without consideration of the dynamics, 
unintended consequences may follow. Thus in this paper we consider how a modelling process can support the thinking of a management team when considering stakeholder dynamics.

The modelling process is divided into a series of steps (a 'script') where each step provides a 'deliverable' (Andersen and Richardson. 1997; Eden et al. 2009; Ackermann et al., 2011). A deliverable is a 'take-away' for the decision makers - they are able to act differently. The steps are formulated with respect to assertions/propositions about the nature of stakeholders, and where possible these propositions are supported by stakeholder theory.

The paper follows following structure. Firstly, a 'real case' is introduced. The six steps are then introduced using the format of: activity, proposition that guides the activity along with a brief review of relevant extant literature, deliverable i.e. what the client gains from the step, and the case example showing the implementation of the activity. We then summarise the six propositions and provide a table noting not only the six steps but some modeller notes to facilitate each step. We finish by discussing the value gained by the modelling approach through its capacity to illustrate how a model as a transitional object and boundary object supports the deliberations of managers and reflect on the limitations of the study.

\section{The Illustrative Case}

The illustrative case details policy development work undertaken by an organisation responsible for airport security. The material has been slightly modified to ensure anonymity (although the case was conducted over 15 years ago). The participating group was the senior management team of 16 people. Following the identification of a number of core strategies for the next five years, the senior management team wished to explore the effectiveness and robustness of those possible strategies. The team were acutely aware that other stakeholders might easily 'mess up' the chance of success of several of their agreed strategies.

The implementation of the modelling approach presented in this paper constituted a part of a 2-day facilitated off-site strategy workshop with the stakeholder component comprising around half a day. The strategy workshop facilitation involved a combination of the use of a group support system (GSS) namely Group Explorer (Ackermann and Eden 2010) and the formulation of a system dynamics simulation model (Andersen et al. 2010). The use of a GSS meant that contributions could be captured 'simultaneously' allowing for greater productivity as all could 'speak' at once, along with providing anonymity and thus reducing possible conformity pressures. The emergent model provided an organisational memory, and supported the senior management team's management of the inherent complexity faced by considering the range of strategies, stakeholders and dynamics. 


\section{The Modelling Process - Six Steps}

It is worth noting that the first four steps are likely to be of general use for exploring the stakeholder impact of a large set of potential policies or potential modelling outcomes, for example, optimisation efforts, decision analysis etc. These first steps derive from work reported elsewhere (Eden and Ackermann 1998; Ackermann and Eden 2011b). In the method outlined below, whilst the Group Explorer GSS used the causal mapping technique when undertaking the stakeholder modelling, it is important to note that although the qualitative models may look similar to cognitive or causal maps they are not intended to be used, or read, in this way. Instead, the representation system might be seen as a simple directed graph where the arrows $(x-y)$ represent $\mathrm{x}$ may mean that $\mathrm{y}$ occurs, or x may help deliver $\mathrm{y}$, person $\mathrm{x}$ may influence the behaviour of $y$. In addition, whilst a GSS was used, it is possible to undertake the activities manually.

\section{STEP 1: Identify and Structure Stakeholders}

Identify Possible Stakeholders: that is those actors able to influence the strategic future of the focal organisation - they are stakeholders because they have a 'stake'/ interest in the behaviour and strategic future of the focal organisation, in particular where the intended strategies impact their own aspirations. These stakeholders may be internal stakeholders: key departments, groups, unions, operating companies of the focal organisation as well as external stakeholders each having an interest in monitoring and influencing the strategy of the focal organisation (e.g. regulators, customers, competitors).

Map the Possible Stakeholders onto a Power-Interest (PI) Grid: use a $2 \times 2$ matrix where the $y$-axis represents the degree of interest the potential stakeholder has in the behaviour and future of the organisation - particularly the strategies being proposed, and the $\mathrm{x}$-axis the degree of power the stakeholder has to influence the future of the organisation. The grid/matrix represents the relative position of each possible stakeholder in terms of their interest and power reflecting a spectrum. Those actors positioned in the top half of the matrix are the STAKEHOLDERS because they have a high degree of stake (interest) in the future of the organisation and its proposed strategies - they care about its success or failure and may wish to take action encourage failure or success. Those in the top right quadrant are critical to the future of the organisation because they may wish to take action to encourage failure or success AND have the power/influence to do so. Others in the bottom right of the grid are ACTORS/CONTEXT SETTERS who have the power to influence the future of the organisation, but as yet do not have a specific intent to do so as judged by those participating in the modelling effort.

Proposition 1 STAKEholders are those with an interest in the organisation. They may or may not have the power to express their interest through action that will influence that future. Many authors see stakeholder interest as a key criterion when considering stakeholders. Frooman, (1999) notes the need to consider stakeholder interest and influence as does Mitchell and colleagues (Mitchell et al. 1997). Considering who is interested is one means of not only identifying stakeholders but also 
prioritising them. Moreover, understanding the motivation which defines the stake of a STAKEholder is also of value (Eskerod and Lund, 2013).

DELIVERABLE clarity about who are the STAKEHOLDERS, and those who might unintentionally affect the future of the organisation - they are CONTEXT SETTERS (Figs. 1, 2, 3).

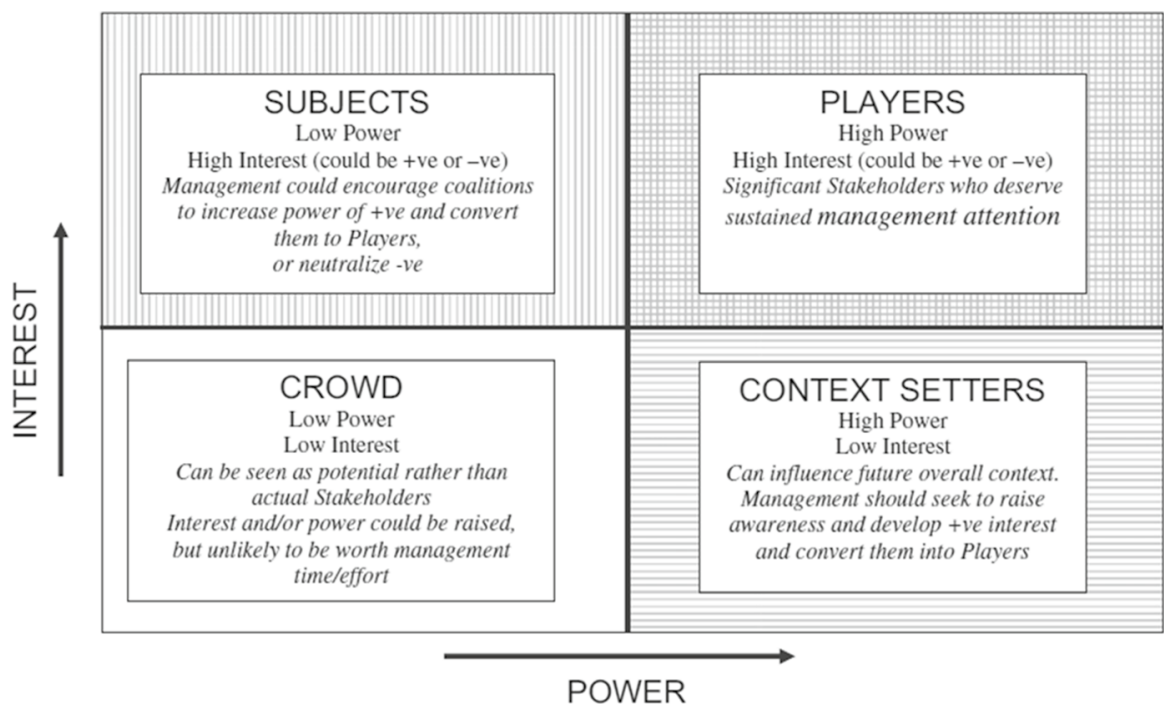

Fig. 1 The Power-Interest Grid ( taken from Eden and Ackermann, 1998; Ackermann and Eden, 2011b)

\section{Step 1-Case Example}

\section{Identify Stakeholders}

media

local politicians

vendors

human rights

pressure groups

$\begin{array}{ccc}\text { tourist passengers } & \\ & \text { aviation system } & \\ \text { (airport Air Traffic } & \text { Control etc) } & \text { airlines }\end{array}$

policy makers

Airport Police

business passengers

Officers Security Officers

customs \&

immigration

Fig. 2 Stakeholders Identified: here the managers begin the process of identifying stakeholders, without consideration for their power and interest 


\section{Organise into Power-Interest Grid}

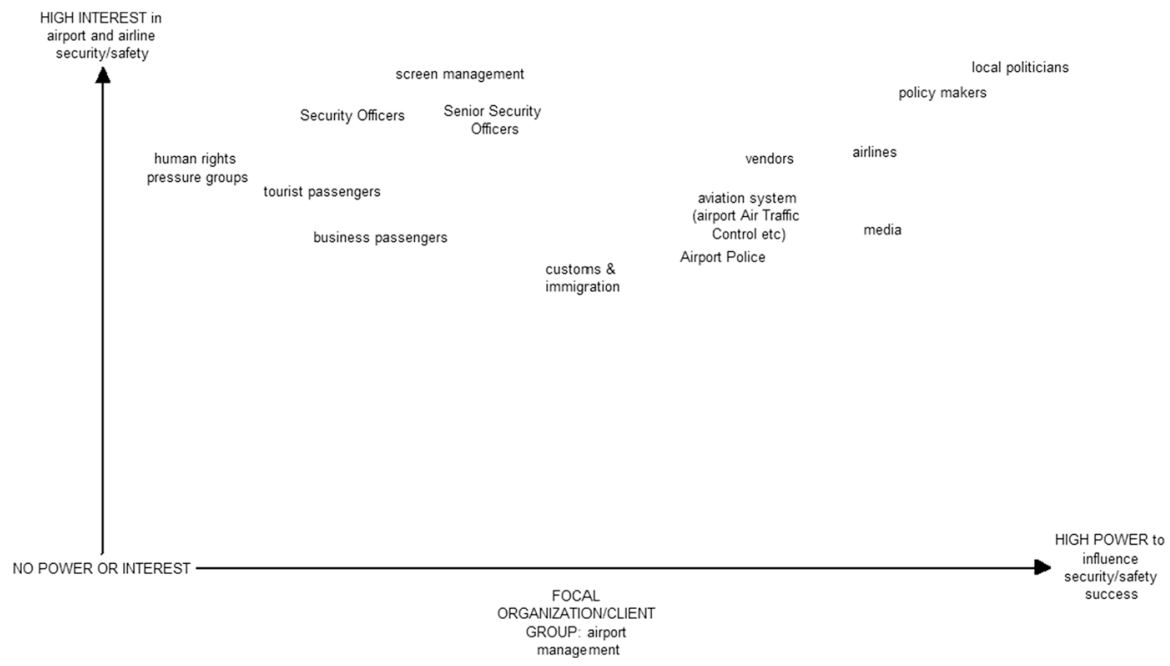

Fig. 3 Using the Power Interest Grid: with stakeholders being positioned on the dimensions of power and interest

Case Explanation: In the above grid: (1) policy-makers and local politicians were taken to be the same people and; (2) screen management was disaggregated into Senior Security Officers and Security Officers. This reflects the importance of checking for overlaps and assessing the degree of aggregation/dis-aggregation (so that the stakeholders are captured at a level able to be managed). There was debate about whether Immigration and Customs should be included in the Aviation System, however because the purpose (goals) of Immigration and Customs was so different from the Aviation systems as a whole they were taken to be separate. In addition, the group were unable to place media with any consensus and 'discovered' that the reason was that they were so fluid in power and interest- their position was absolutely issue related. Thus, the Grid was revised as follows (Fig. 4): 


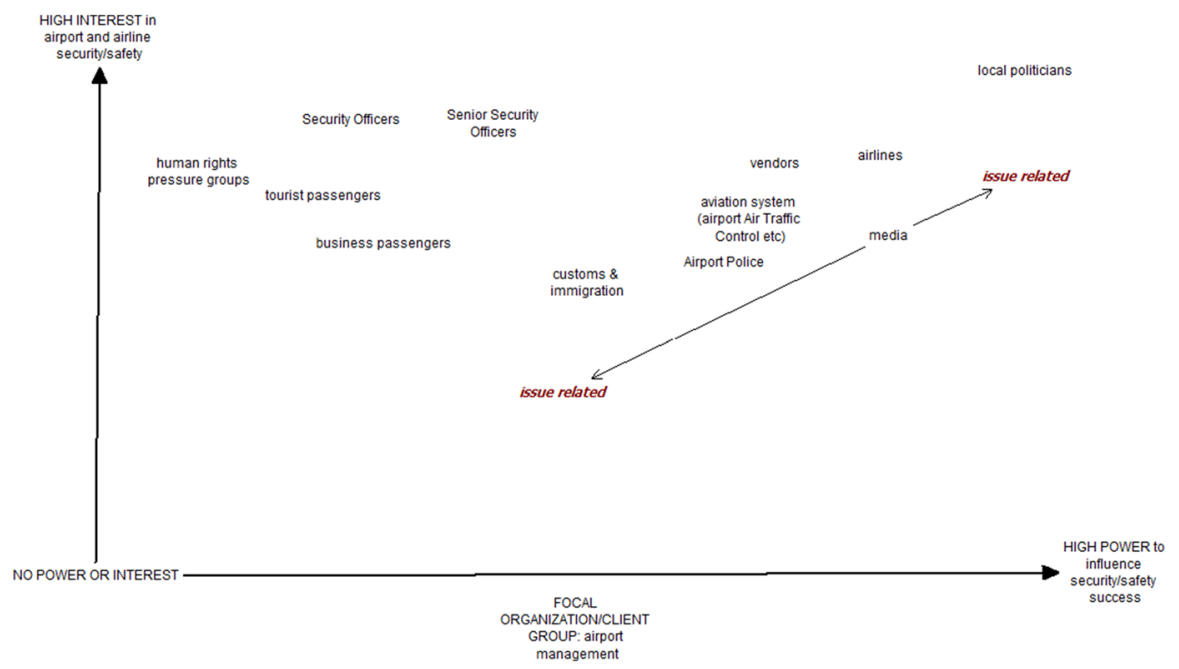

Fig. 4 Fluidity in the Power Interest Grid: the media were considered to be very powerful and interested in some situations but less so when addressing other issues, the arrows show this fluidity of positionthere was some debate about whether the arrow was vertical, where they were considered to be always powerful

Thus, at the end of STEP 1 the management team will have gained some clarity about who are the STAKEHOLDERS, and those who might unintentionally affect the future of the organisation. However, not all those identified will have been shown to be STAKEholders, and some stakeholders will be of greater significance than others. STEP 2, therefore seeks to identify and validate those stakeholders that are, at least initially, a focus of attention for the group.

\section{STEP 2: Identify Key 'Players' from Among the Stakeholders}

Identify KEY PLAYERS: those Stakeholders with high Power and high Interest: (the top right of the high-power/high-interest quadrant). As a means of managing the volume of stakeholders, focusing attention on a group of 10-12 key stakeholders with high interest and high power is a good first step. Unless these PLAYERS's interest and power are understood then any strategy might be thwarted or under-exploitedkey players can sabotage or support the organisation's strategies. Those intent on sabotaging may be managed by seeking to change their interest or power, and those likely to support may be encouraged and resourced in the behaviour.

Proposition 2 The priority for analysis is to focus attention on at least those STAKEHOLDERS with the most POWER to influence the impact of any proposed strategy of the focal organisation. However, it is also important to consider those stakeholders with less power who may form themselves into a coalition (or can be formed into a coalition) and so become powerful. As with interest, the dimension of power or influence is a means of differentiating and prioritising where attention is required. 
(Eskerod and Jepsen 2016) and Jepsen and Eskerod 2009) discuss categorizing stakeholders according to criteria such as interests and influence. Using power and interest as dimensions when considering stakeholder management is not new (for example, Eden and Ackermann 1998; Bryson 2018; McElroy and Mills 2010) and has been applied in a range of industries e.g. human resource development (Garavan 1995), construction projects (Olander and Landin 2005) etc. Others have noted power, legitimacy and urgency (Mitchell et al. 1997) as dimensions.

DELIVERABLE identification of key stakeholders - key PLAYERS-who can significantly influence the focal organisation, and so must be managed carefully.

\section{Step 2-Case Example}

\section{Identify KEY PLAYERS: Those Stakeholders with High Power and High Interest}

The facilitators had been concerned that the number of stakeholders identified seemed small and tried to push the team to identify more. Given time constraints (the entire modelling process had to be completed within half of a day) the management team were certain, on the basis of past experience, that they had identified the most important from the perspective of potential dynamics. The team first looked at the stakeholders with the most power and interest but decided that they wished to consider all of the stakeholders they had identified. This proposal seemed sensible given that the number identified was less than often the case.

Thus, STEP 2 has identified those stakeholders who can significantly influence the focal organisation, and so must be managed carefully. These stakeholders, who are seen as key players, may change as the analysis steps lead to further discussion and negotiation among the management team. STEP 3 asks the team to consider what these key players wish to achieve (their goals) in the problematic situation.

\section{STEP 3: Surface the Core Goals of Key Players}

\section{Identify the core goals of each of the key PLAYERS.}

Core goals describe the driving force of strategic and/or operational behaviour of the stakeholder. These core goals adequately differentiate the purpose of the organisation from other organisations (and so will not be a generic goal such as "make profit" or "serve the public"). Focusing on around 4-5 core goals which may comprise some sub-goals that each support the core goals helps ensure that the material captured reflects the main aspirations of each of the Players whilst not resulting in an over complex model. In addition, include the core goals of the key internal stakeholders of the focal organisation. Any goals common to all stakeholders are likely to be superordinate, at least initially, and generic/vague. Seek to capture the core goals in a manner that clearly reflects sufficient detail regarding their nature but at the same time is concise. Six to eight words can work well. In some instances, the goals may be worded negatively, for example 'no violation of passenger rights'. These negative goals (or ramifications) are equally important to note.

Check that the surfaced material reflects the core goals of the key players. Often the surfacing of goals gives rise to statements which are not desired outcomes but 
rather strategies/options. Thus, the group needs to agree on which of the suggested goals are 'genuine' goals and which are optional (for example, strategies). For example, while the group had initially shown "better communication link between aviation system and security" as a goal for the airlines, discussion quickly led to agreement that this was only one of several optional means to the end goal "ensure high security" rather than an end in its own right. It is usual for approximately one-third of identified goals to be optional strategies rather than 'good outcomes in their own right'. These need to be recoded (possibly using a different style/colour) as possible strategies that the stakeholder could use to deliver their core goal. They will become important as stakeholder interactions are explored later.

Proposition 3 The core goals of key players must be identified because STAKEholders respond to the behaviour of others if their own INTERESTS (GOALS including 'negative avoidance' goals (see Bryson et al. 2016)) are believed to be at risk or can be supported. The modelling process step also attends to the premise that there is likely to be conflicting interests due to the range of key player goals (Narayana et al. 2014). Understanding not only the goals but also sub goals, i.e. recognition of a network or hierarchy of goals takes cognisance of March and Heath's logic of consequentiality (March and Heath 1994). In addition, it is worth reflecting that the goal systems have the potential of being influenced by what others might think (Eskerod and Jepson 2013).

DELIVERABLE: Possible Key Strategies and Core Goals of all Key Players

\section{Step 3-Case Example}

\section{Identify the Core Goals}

See Table 1 for a summary of the core goals identified for each stakeholder. In some instances the goals are the same for 2 or more stakeholders - for example increase screening efficiency' is a goal for both tourist passengers and airlines.

Several 'negative-avoidance goals' are proposed, where the expressed goal is one of avoidance

no violation of passenger civil rights [human rights pressure groups].

no wait at the checkpoint [airlines].

no wait at the checkpoint [tourist passengers].

avoid service failures [SSOs and SOs].

avoid not getting re-elected [politicians].

decrease the impact of disruption on the aviation system [Police].

Thus, STEP 3 has facilitated a team discussion about possible key strategies and core goals of all key PLAYERS: what does the team presume each of these players wish to achieve in the situation. Typically, the most revealing outcomes for this step are the realisations about the extent to which negative-avoidance goals are important drivers of possible behaviours of the key players. STEP 4 recognises that when one stakeholder achieves their own goal then it may help or hinder another stakeholder achieving theirs. And so, STEP 4 seeks to map out these possible interactions between goals. 


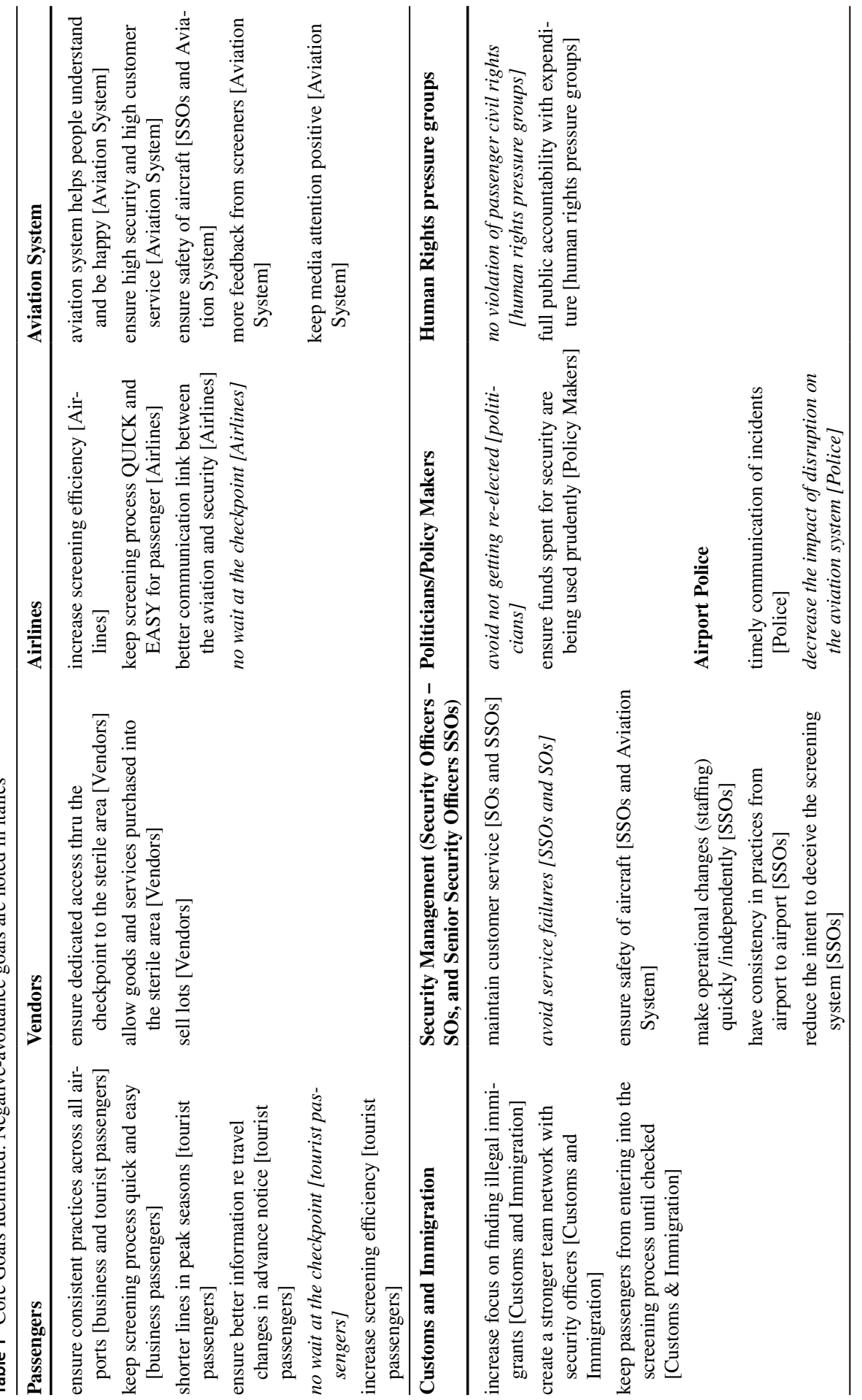




\section{STEP 4: Capture the Chains of Interaction between Goals}

Map the interaction (support) between the core goals of stakeholders. Explicitly consider in what way does the attainment of each core goal impact/influence the attainment of other stakeholder core goals. In other words, express judgment about when the core goal of one stakeholder helps another stakeholder achieve their core goal (or the opposite where the core goal of one stakeholder hinders the goal achievement of another stakeholder).

And visually analyse the stakeholder goals interaction model, particularly with respect to the location in the network of the goals of the focal organisation's goals. For example, are they drivers of a lot of other super-ordinate goals (potency), or alternatively driven by the goal seeking behaviours of many other stakeholders. Are there focal organisation goals that are highly central in the map - they support many other goals and are supported by many other goals.

Proposition 4 The response of a key player/stakeholder is influenced by their own goals but also potentially by the goals of others. Nevertheless, care needs to be taken to understand that sometimes responses are 'knee-jerk' with respect to tacit goals or unarticulated goals. This is what is referred to as habitual or impulsive behaviour (Schiffman and Kanuk 2009). Often outsiders are able to identify goals more accurately than those inside an organisation where overly rational or historical goals are presumed to drive behaviour (touching on Argyris and Schon's work on espoused theories versus theories in action (Argyris and Schon 1974)).

Goals form systems and understanding the motivation of stakeholders beyond the highly generic profit and growth focus can yield a subtler understanding (Bryson et al. 2016; Ackermann and Eden 2011b). These goals systems facilitate analysis revealing goals that are, for example, central to the overall structure.

DELIVERABLE: focal organizational goals selected because of their centrality and potency.

\section{Step 4-CASE EXAMPLE}

\section{Map the Interaction (support) Between Core Goals of Stakeholders}

This goal map (Fig. 5 below) shows all of the proposed goals. Many of which subsequently were noted to be strategies rather than goals (the statements not in bold font). In square brackets at the end of each statement is noted the stakeholder whose goal is stated. To aid identification of goals with respect to stakeholder they are colour coded.

Without the potential suggested strategies, the goals interaction map became less complex (Fig. 6 below):

Thus, STEP 4 has mapped out the interaction between the goals systems of the key players. Although the focus of the step has been on players, depending on the number of stakeholders it will be helpful to gather the goals for as many stakeholders as possible, gradually considering those with less power. The process will 

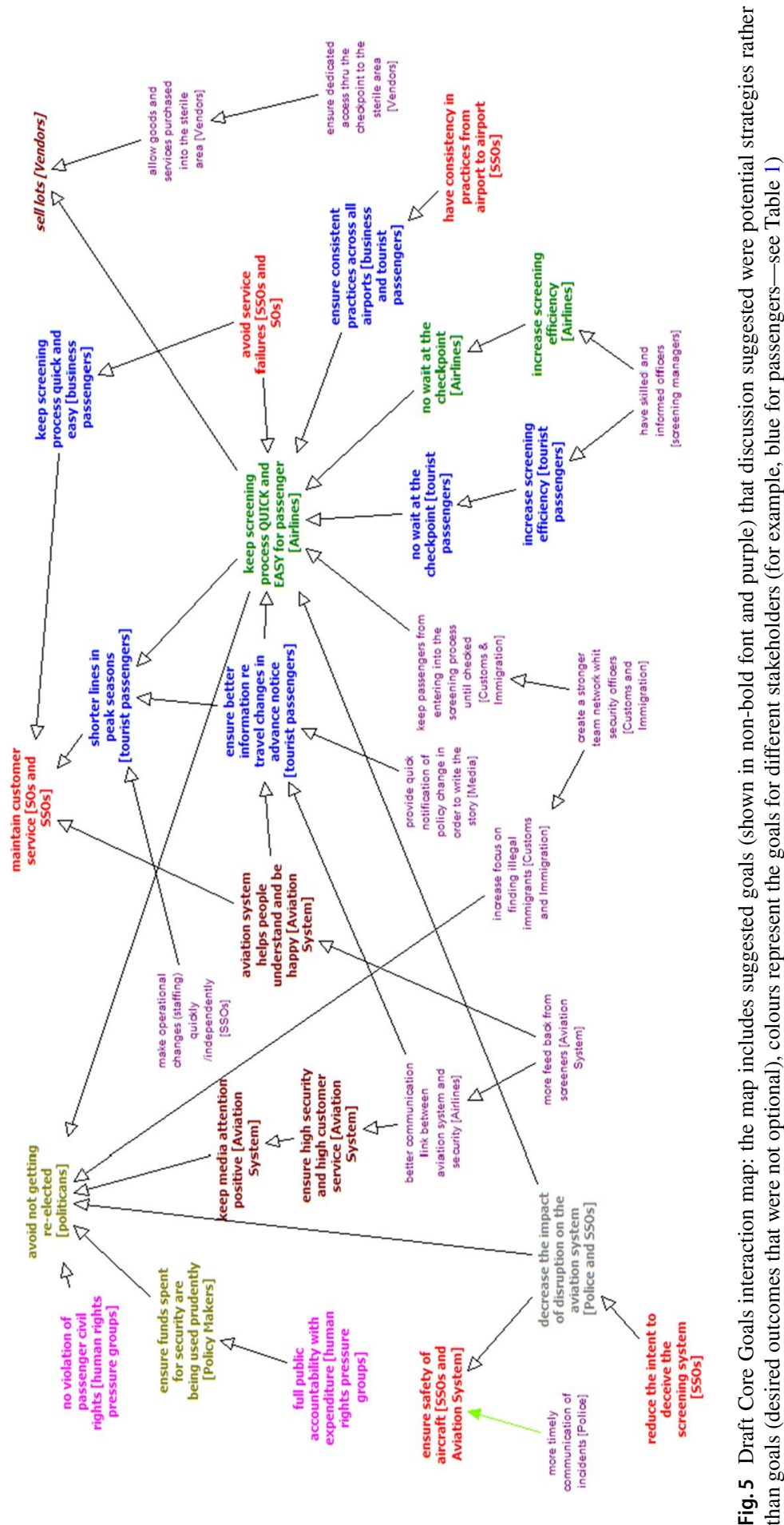
have facilitated the identification of goals that are central to the overall structureselected because of their centrality and potency. With a view of the interacting goals system across stakeholders it becomes possible to test out strategies. STEP 5 seeks to refine possible strategies (some of which have already emerged in earlier steps) through exploring the ramifications of stakeholder responses.

\section{STEP 5: Exploring and Testing Out Strategies}

Explore and enhance/refine promising strategies: expected to i) help the focal organisation attain its core goals and ii) through refinement, attain as many goals of the key player stakeholders as possible. Promising strategies are likely to be those that have many ramifications (out arrows) and so are aimed at 'hitting' a core goal that is 'at the bottom' of the stakeholder goals network hierarchy but with positive ramification to many other goals.

Proposition 5 Strategies can be continuously improved through a process of understanding the potential responses of stakeholders. This is similar to the principles of game theory (for example, Bennett and Dando 1981; Fang, Hipel, and Kilgour 1993; Bryant 2010) in terms of testing out strategies and determining responses. However, through the use of the qualitative model, the process is both quicker and more accessible. In addition it touches on research that recognises the significance of using concepts such as systems thinking to model strategic interventions through involving stakeholders affected by strategies (Elias 2019) as strategies are often impeded by roadblocks created by stakeholders who feel that their stakes are not addressed adequately.

DELIVERABLE improved strategies - strategies become enhanced so that they are less likely to induce dysfunctional responses from stakeholders (including responses of stakeholders to the responses of other stakeholders in response to the strategies).

\section{Step 5-CASE EXAMPLE}

\section{Explore and enhance/refine promising strategies}

In the case the team were concerned about a potential crisis: a specific and possible air-side terrorist attack. Analysis of the Goals system shows that a powerful strategy would be one that helps 'decrease the impact of the disruption on the aviation system'. To do so will help politicians, airlines, vendors, tourist passengers, and help with the core goals of the focal organisation (SOs and SSOs): 'maintain customer service'.

Thus, the draft strategy that was regarded as most powerful was seen to be an apparently simple one that had been suggested as a part of gathering core goals: better communication link between aviation system and security [Airlines]. This strategy was suggested because it aimed at decreasing the impact of disruptions on the aviation system - a core goal for both security officers and the police (meeting a goal of the focal organisation and one other stakeholder). 


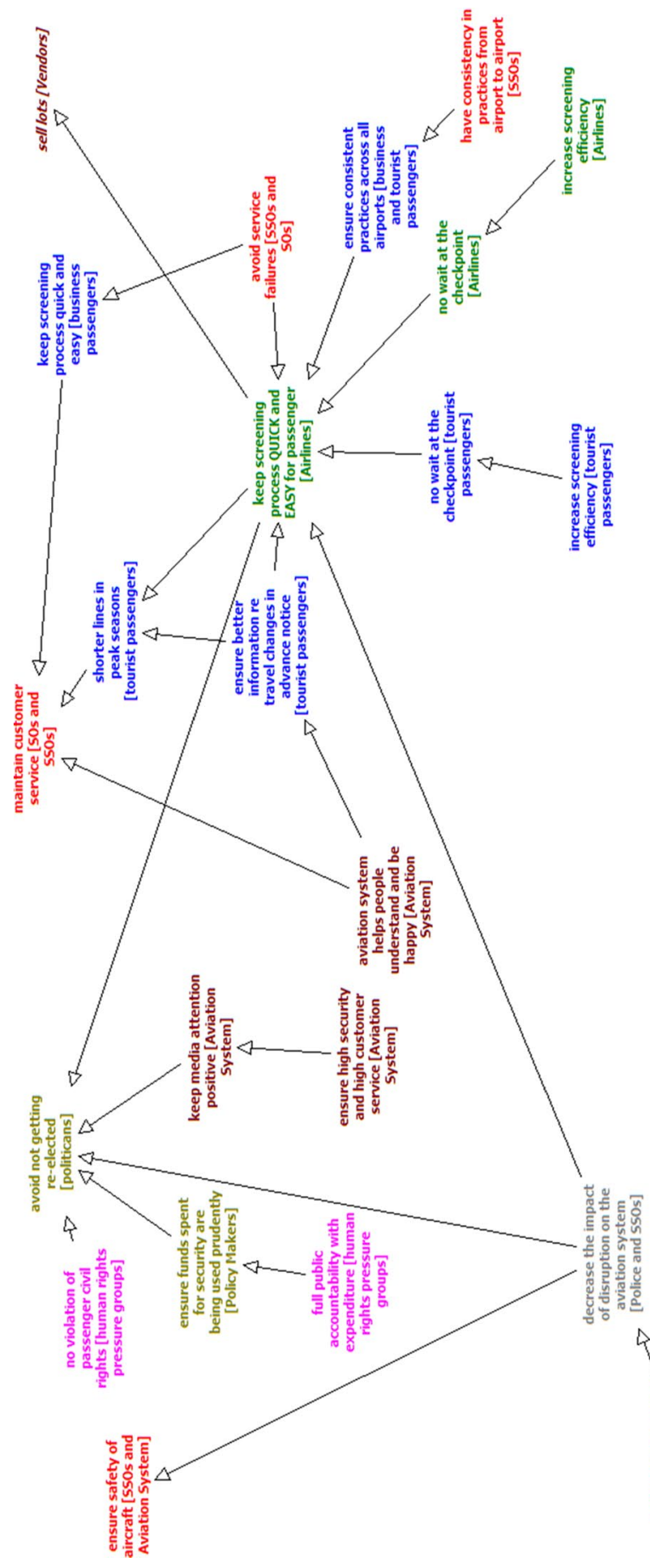

넝

드

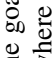

$\stackrel{\frac{7}{3}}{3}$

홍

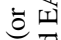

氕

产记

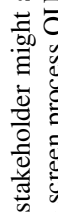

ठิ ญे

पै

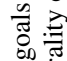

ㅠㅇ

$\stackrel{\infty}{\Xi}$

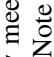

วิ

范 
In considering refinement of the strategy, the team firstly queried the meaning of the rather vague strategy statement - believing it would be helpful to be clearer about how 'better communication' was to be achieved. Thus, the strategy was modified to say: more timely communication of incidents and better communication links and further to explicitly state that the management team's expectation was that this would be achieved through the use of technology that had been under test. Thus, the strategy statement became: use advanced technology to permit SSOs to get information from the police in a more timely manner.

The next stage was for the team to consider whether the strategy could be refined so that it was able to not only meet the goal of decreasing the impact of disruptions on the aviation system and its ramifications but also other goals of other stakeholders gaining further support.

Reviewing the full map showed additional suggested strategies relating to communication: for example, more feedback from screeners (wanted by the Aviation System) — initially noted as a goal. Using the same technology to help with communication between aviation and security should be considered provided it did not compromise the focal goal. However, in further discussion the team noted that simply using technology did not help reduce the intent to deceive the screening system unless those seeking to do so were aware of the new system. The strategy was modified so that it would also help attain this (negative) goal: use technology in a visible manner to support timely and collaborative communication between police and SSOs (including a visible link from gate staff to SSO and Police). This revised strategy was expected to directly help attain: decrease the impact of disruption (police and SSOs); reduce intent to deceive (SSOs); ensure safety of aircraft (SSOs and Aviation System); keep screening process quick and easy for passengers (Airlines). Thus addressing goals of many stakeholders: SSOs, police, aviation system, airlines. In addition, there was the possibility of implementation helping provide a better link between the aviation and security (tourist passengers and aviation system goals).

With initial exploration and refinement undertaken in STEP 5, STEP 6 continues to refine strategies through a qualitative simulation modelling of the dynamics of stakeholder responses.

\section{STEP 6: Simulate the Responses of Stakeholders, not only to the strategy but to each stakeholder's response to the strategy.}

Simulate, using a thought experiment: (Cargile 1991), the response of stakeholders to the implementation of the most promising strategy that is designed and expected to attain the core goals of the focal organisation and other stakeholders.

The thought experiment will need to consider that often the implementation of a strategy can promote 'knee-jerk' responses rather than well-thought through responses. 
Use the goals map to identify the goal of stakeholder(s) that might be expected to be impacted by the strategy (that is, consider at least the out-arrows from the focal organisation goal under consideration).

Consider, in the first instance, a stakeholder goal that is also relatively potent or central in the goals map. Consider the likely responses of the stakeholder to the strategy.

Notwithstanding the possibility of ill-thought through 'knee-jerk' responses, the response must be with respect to their identified core goal and associated sub-goals, and the possible use of their identified strategies. It is crucial to re-check the presumed stakeholder goal and to 'step into their shoes' and think from their perspective (see 'role think' procedure in Eden and Ackermann 1998: 133).

The response of the stakeholder will typically demand a revision, sometimes subtle, of the proposed focal organisation strategy in order to ensure that the stakeholder response is positive, neutral or at least not negative enough to matter.

Continue with a consideration of the potential responses from other stakeholders who have goals that are impacted by the strategy of the focal organisation (with reference to the goals map).

Revise the proposed strategy - that is continuous cycling until "finished with" (Eden 1987) resulting in a satisfactory strategy that attends to the views of those attending.

Continue exploring the goals map by anticipating possible responses of stakeholders impacted (in the goals map-thus moving up the goals hierarchy) until a new future situation arises that can be exploited by the focal organisation that reinforces their goal.

This step is the most difficult and yet also the most crucial. The purpose is to find ways in which stakeholder responses increasingly support the proposed strategy. The strategy is modified until the best long-term support is likely. As we see from the example (Fig. 8 below) it is likely that there will still be some dysfunctional responses and these need to be balanced with the supporting responses. The aim is to try and devise a strategy where internal and external stakeholders help deliver the strategy over time.

Proposition 6 A simulation of stakeholder responses to a potential strategy of the focal organisation is likely to be realistic enough to enable the development of improved strategies. This attends to the "complex and dynamic nature of stakeholder positions and behaviours in these projects point to the need of involving stakeholders while formulating and implementing strategic interventions. Therefore, there is scope for developing methodological approaches that can aid in formulating strategic interventions through stakeholder involvement and collaboration" (Elias 2019: 313).

DELIVERABLE self-reinforcing strategies that seem least likely to produce significant negative responses from stakeholders, most likely to get support and a better strategy than would have been the case without consideration of stakeholder interactions. Enhancing an understanding of the goals and behaviour of stakeholders. 


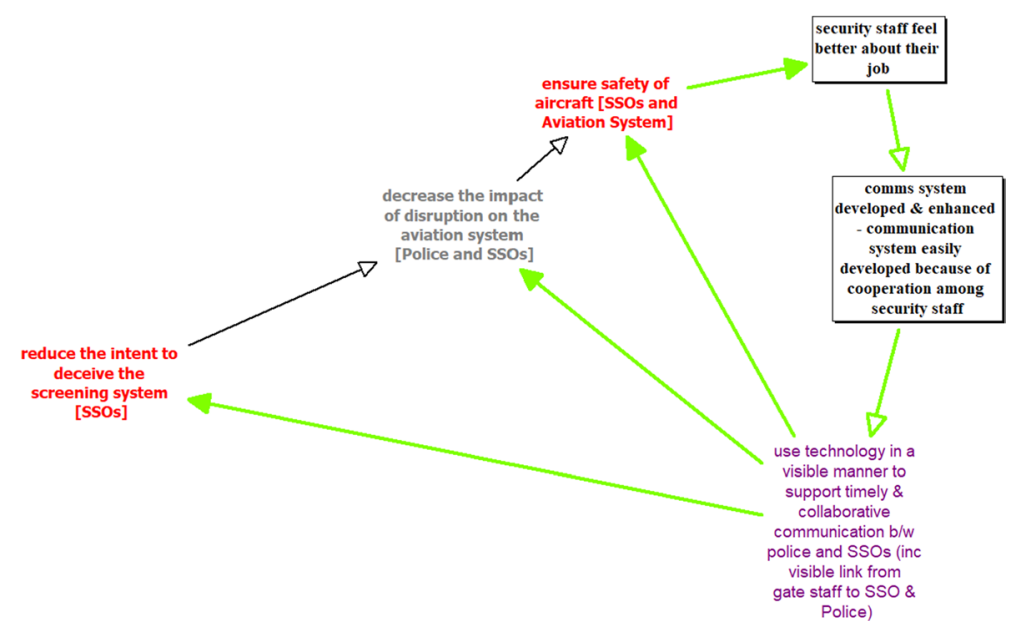

Fig. 7 Staff response reinforces the strategy: The two responses (in black and boxed) following the implementation of the enhanced strategy -green arrows show support for the outcome which are also a part of multiple feedback loops that reinforce the effectiveness of the strategy

Step 6-CASE EXAMPLE: Note: the description of this stage has been significantly simplified in order to promote an understanding of the process through example.

Simulate, using a thought experiment:

Considering the response of human rights organisations to the goal of no violation of passenger civil rights there might occur:

Worry that the visibility of the strategy might mean too many apparent racist pickups might be identified by the media and reported, with a consequential media story developing about the 'incompetence' of SOs. Thus, the strategy has a risk of a negative impact on i) the human rights organisations goal of "no violation of passenger civil rights, and ii) the goal of "keep media attention positive" with the consequence of risking the politicians' goal of "avoiding not getting re-elected".

Considering the response of Policy Makers with respect to the goal of ensuring funds spent for security are being used prudently:

The proposed enhancement of the strategy so that it facilitates a better communication link between aviation and security might be seen as a negative impact on "ensure funds for security are being used prudently" with the possible impact on re-election. The team decided their strategy was dependent on small marginal cost to this outcome, and so was not a significant concern. Although they considered that there was a danger of incremental growth in expenditure that must be protected against.

Considering SSOs and SOs response to ensuring the safety of aircraft and to the attainment of their goal of ensuring the safety of aircraft and maintaining customer service:

The team believed that this would mean staff feeling better about their job in response to the implementation of the strategy - they were aware of the low morale 


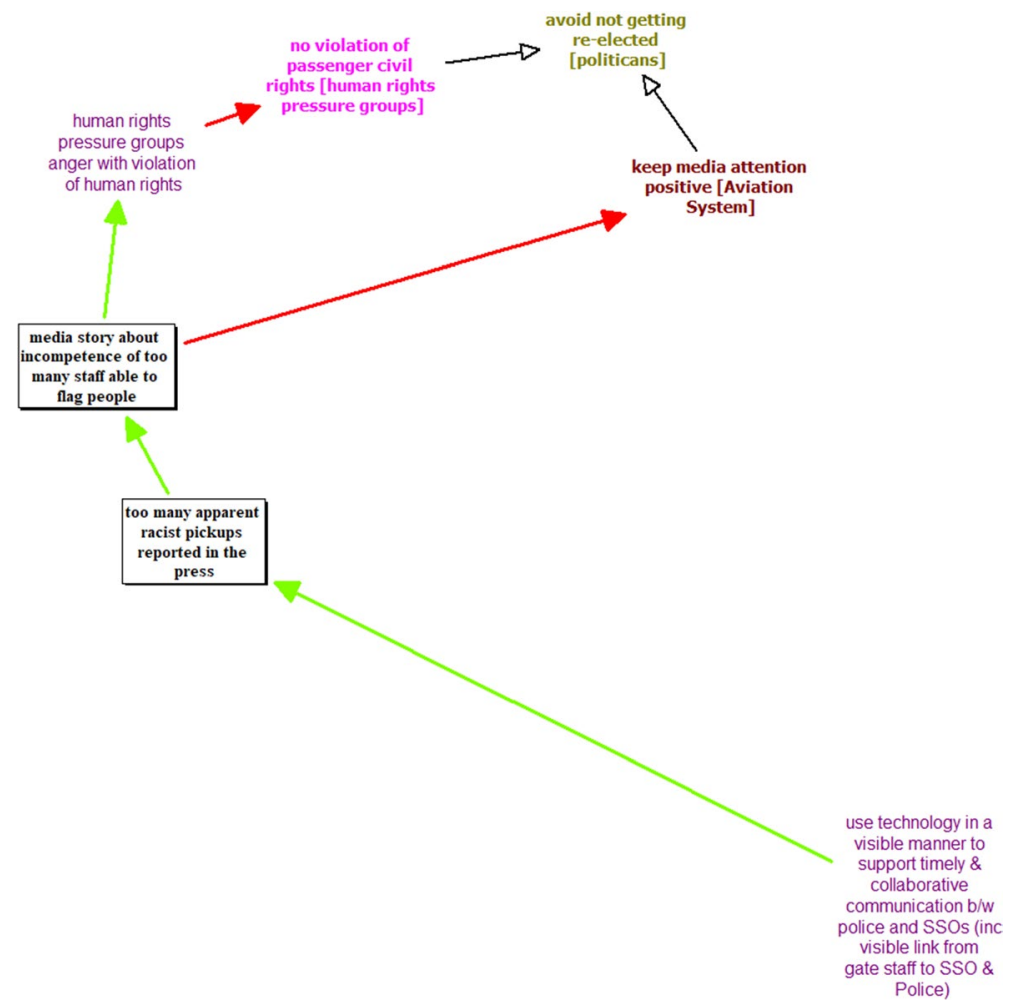

Fig. 8 Possible worrying dysfunctional outcome: Responses (in black and boxed) following the implementation of the enhanced strategy - the red arrows shows where an outcome has the opposite impact to that stated by the outcome of the arrow, and green arrows show support for the outcome which are also a part of multiple feedback loops that reinforce the effectiveness of the strategy

among staff. This would mean they would be more likely to support the original strategy and enable a continuing easy and effective implementation and development of the communication system. But significantly, they believed that there would be other spin-offs to reinforce screening efficiency for both airlines and tourist passengers.

This response was seen to be self-reinforcing.

Figures 7, 8, 9, 10 show extracts of the overall exploration of dynamics (shown in Fig. 11). Figure 7 shows the expected response from an internal stakeholder (the staff) - a positive and reinforcing response. Whereas Fig. 8 shows what the group regarded as a likely dysfunctional response following the possibility of too many apparent racist pickups reported in the press and its impact on politicians. Figure 9 shows how significant the staff response might be-the staff feeling better about their jobs. This anticipated response is crucial to the effective reinforcing dynamic because it is at the core of the many feedback loops identified. The management team not only appreciated its significance with respect to the developing strategy, but also promoted the significance of the feeling staff had about their job for strategy 

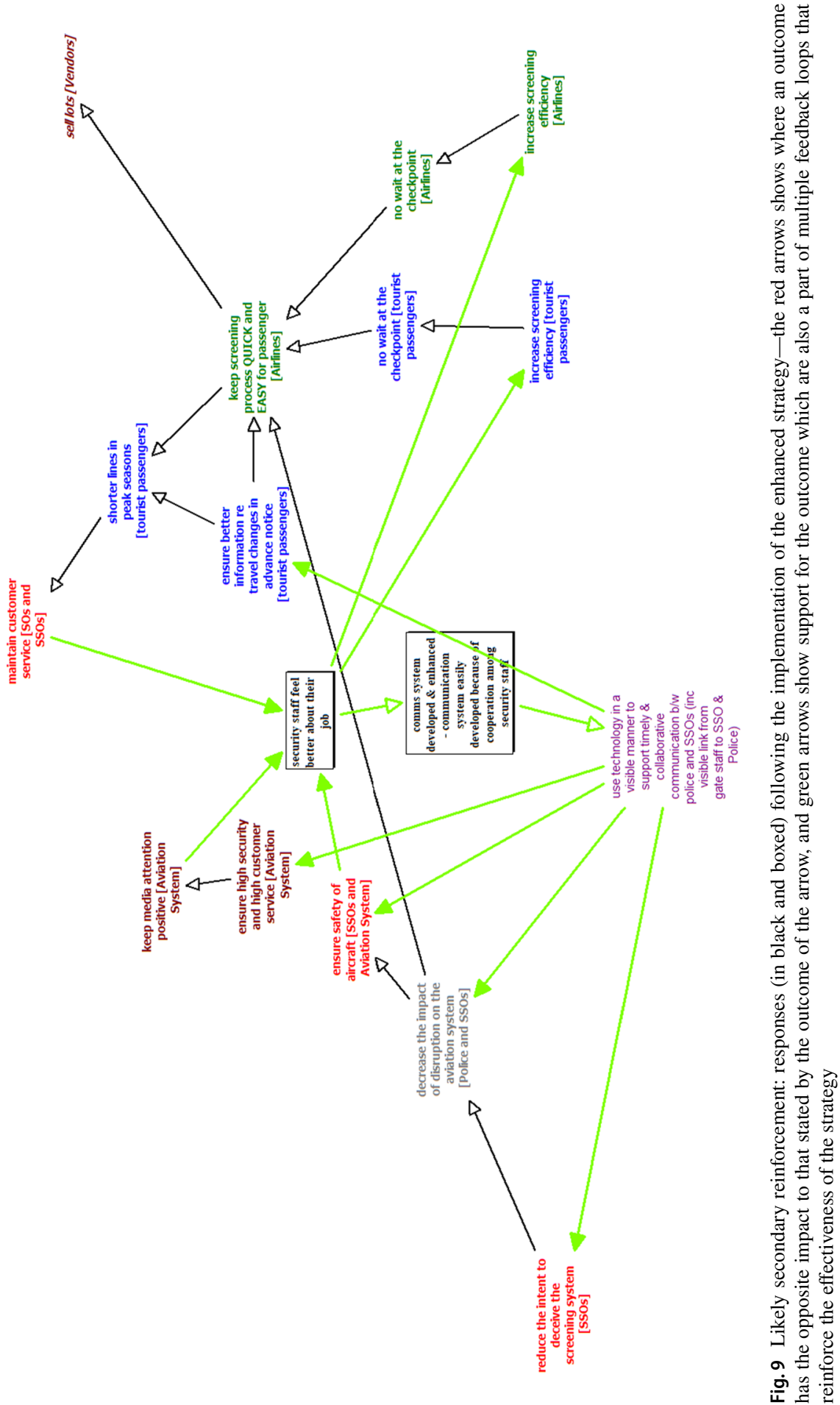


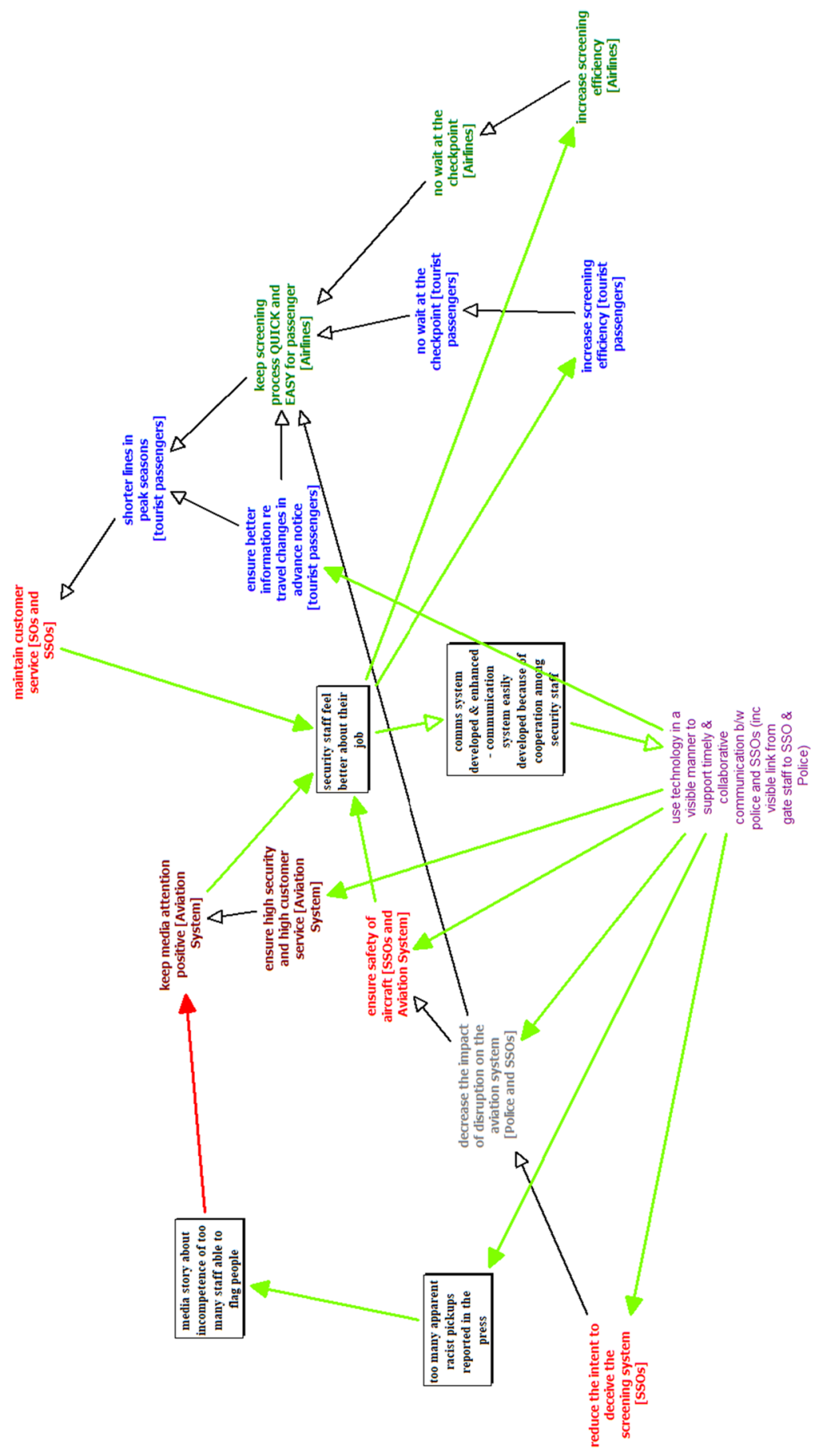

플 픔

电

两

更

호을

흘

흘

항

홍

훙

है

흘

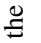

.

응

จิ

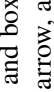

冚

의

矛

흥

逭

苛总

莺 焉

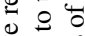

荧

…

bo 苟

흉 응

可

递

政

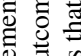

这

드

인

政

品

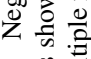

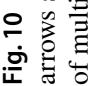




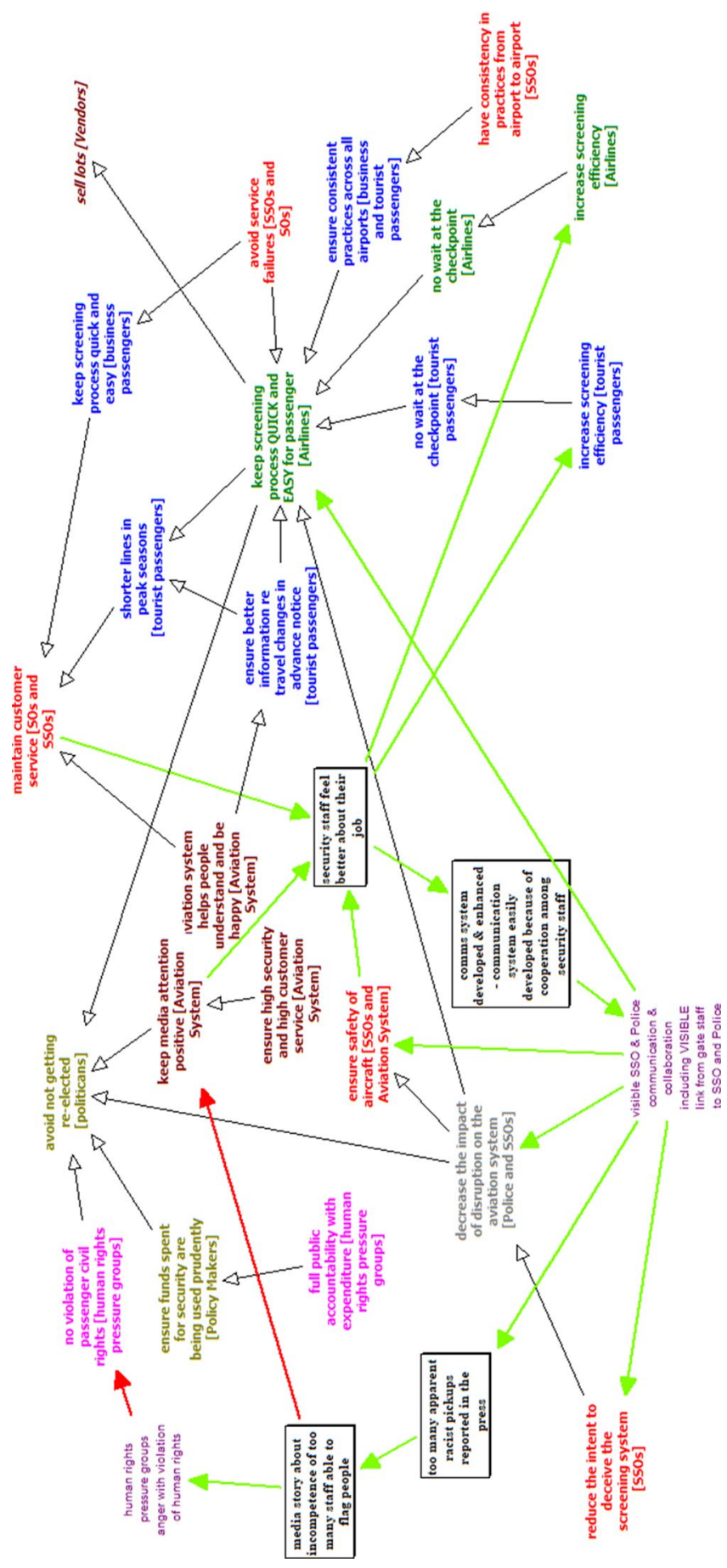

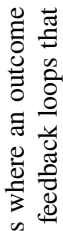

高产

点

害苍

己ृ

$\stackrel{\overbrace{}}{\cong}$

ठำ

范

क⿺⿻一⿰冫⿰亅⿱丿丶丶⿱⿰㇒一乂

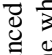

클

๑

농

훙

氖

䒠

巳n

.

응

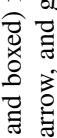

莺

.

o ह

ठ․

웅

$\Xi$

응

急

중 행

코 폴

을

芩

氙.

응 응

$=$ 巳

울 월 
development in general. Figure 10 shows how the management team needed to make a judgment about the 'battle' between positive and negative outcomes of their strategy.

Figure 10 shows the negative and positive interactions that promote two forms of dynamic: positive feedback of a virtuous self-sustaining cycle, and negative feedback which tends to negate the impact of the strategy as it is implemented. The two sets of responses suggest a competition between the impact of the negative feedback loop and the positive/virtuous feedback loop, and risky negative outcome of the impact on politicians.

Figure 11 shows undesirable consequences may follow as: security staff feel better about their job, leading to the communications system being developed \& enhanced-made easier because of cooperation among security staff and subsequently leading to visible SSO \& Police communication \& collaboration including VISIBLE link from gate staff to SSO and Police, leads to too many apparent racist pickups reported in the press, leading to media story about incompetence of too many staff able to flag people, and so NOT keep media attention positive [Aviation System]. The figure also shows a virtuous cycle is believed to occur as a result of: security staff feel better about their job, leads to communications system developed \& enhanced-communication system easily developed because of cooperation among security staff, meaning visible SSO \& Police communication \& collaboration including VISIBLE link from gate staff to SSO and Police, and so decrease the impact of disruption on the aviation system [Police and SSOs], which ensure safety of aircraft [SSOs and Aviation System], reinforcing security staff feel better about their job.

\section{Discussion and Conclusions}

The steps presented in this paper can be argued to be those that, in effect, a wise and competent manager would be able to follow 'in their head'. Thus, what is the point of qualitative modelling of the sort described in this paper? Firstly, the modelling process, when undertaken in a team setting, enables the wisdom and experience and insight of each manager to be combined and so new insights developed that would not arise without a group process- it provides group support. Visual interactive modelling, albeit qualitative, facilitates the sharing of knowledge so that new insights are more likely to occur. This construction of a boundary object (model) that is "plastic, interpreted differently across communities but with enough immutable content to maintain integrity" (Wikipedia) is also the basis for being able to negotiate enhanced stakeholder strategies. Secondly, the model is continuously in transition so that the group see the continuing enhancement of their thinking, with the model as a transitional object that can also act as an organisational memory. Clearly, good facilitation is important to the modelling process, and so we have included as an appendix some further notes to aid facilitation and analysis with respect to each step.

Is it worth it? As Bryson (2004) and Bryson et al. (2002) suggest, analysis is worth it when "stakeholders matter". In some situations, therefore, it will be worth the effort 
of those seeking to support groups negotiating towards a strategic direction to think through stakeholder responses. Often recommended strategies remain untested for stakeholder reaction. Whilst this process is unlikely to fundamentally change the recommended solution, it is likely to enhance and tune the proposal. The process documents the reasons for the enhancement and so makes it easier to debate and query.

When the potential responses of stakeholders are particularly important it may be worthwhile translating the formulation created by the method here into a system dynamics model, or at least into a stock and flow diagram. Stakeholder goals and sanctions are elements of the classic goal-seeking "cybernetics" balancing loop (Richardson 1991). Andersen et al. (2018) demonstrate the power of such a structure "when they show how stakeholders given mosquito nets to control malaria instead used them to haul fish (Gettleman 25 January 2015). Attempting such a formulation forces clarity of thinking: discovering which 'stocks' are common to all or some of the stakeholders - and thus provides the basis for some of the linking of responses and so reinforces the core of the model of interacting stakeholders. In other instances, there is not necessarily a common stock of concern but there can be multiple touch points overlapping where stocks and their maintenance collide.

Within the structure of a goals system the top of the hierarchy tends to represent 'generic goals' that are not the drivers of behaviour but rather summary/general statements about the specific 'business goals' (core goals) of the organization that differentiate the organization from others in the same field. It is these core business goals that drive behaviour. Being explicit about goals in action rather than those espoused helps organizations focus their energies more effectively. Actions do not derive from super-ordinate goals; they give meaning to subordinate goals. For the purpose of simplification, the method suggests the identification of core goals for each stakeholder. The goals of stakeholders are more complex and are a system of interconnected goals (a goals system-Eden and Ackermann 2013).

The significance of particular goals in the goals system shifts as the situation changes, thus behaviour/responses are dependent of identifying the salience of particular goals with respect to the situation. Realistic models can become very complex very quickly (even for interaction of 2 stakeholders), particularly when attention to a complex goals system is important. As such, constant reviewing is necessary, demanding considerable effort. Whilst this might be seen as an imposition, and thus a limitation, it is also a reflection of the context within which organisations operate.

Finally, there is a danger that too much certainty becomes embedded in the modelpresumptions about goals and responses are not seen as informed guesses. Sensitivity testing can help when high levels of uncertainty exist with respect to a stakeholder.

This paper has deliberately aimed to show the translation of theory into practice. The method proposed is presented as an example of the often quoted "nothing is as practical as good theory" (Lewin 1951:169) The focus of the paper has been to explore analytically the role of stakeholders, and their rarely analysed dynamic responses, as managerial teams consider their potential strategies in response to complex problematic situations. The case example demonstrates how theoretical propositions translate into a series of analytical steps that seek to help the thinking of the management team, and in this sense the method is used as a boundary object and transitional object. 
Open Access This article is licensed under a Creative Commons Attribution 4.0 International License, which permits use, sharing, adaptation, distribution and reproduction in any medium or format, as long as you give appropriate credit to the original author(s) and the source, provide a link to the Creative Commons licence, and indicate if changes were made. The images or other third party material in this article are included in the article's Creative Commons licence, unless indicated otherwise in a credit line to the material. If material is not included in the article's Creative Commons licence and your intended use is not permitted by statutory regulation or exceeds the permitted use, you will need to obtain permission directly from the copyright holder. To view a copy of this licence, visit http://creativecommons.org/licen ses/by/4.0/.

\section{References}

Ackermann F, Eden C (2010) The role of group support systems: negotiating safe energy. In: Kilgour DM, Eden C (eds) Handbook of Group Decision and Negotiation. Springer, Dordrecht, pp 285-299

Ackermann F, Eden C (2011a) Making Strategy: Mapping Out Strategic Success. Sage, London

Ackermann F, Eden C (2011b) Strategic management of stakeholders: theory and practice. Long Range Plan 44:179-196

Ackermann F, Eden C, Pyrko I (2016) Accelerated multi-organization conflict resolution. Group Decis Negot 25:901-922

Andersen D, Richardson GP, Ackermann F, Eden C (2010) Using a group support system to add value to group model building. Syst Dyn Rev 26:335-346

Andersen DF, Richardson GP (1997) Scripts for group model building. Syst Dyn Rev 13:107-130

Andersen DF, Richardson GP, Ackermann F, Eden C. (2018) Stakeholder Interaction Theory: merging goal mapping, stakeholder analysis and feedback mapping. Presentation to the System Dynamics Conference, Reykjavik

Argyris C, Schon DA (1974) Theories in practice. Jossey Bass, San Francisco

Bennett PG, Dando M (1981) Shipping in Crisis: a trial run for live application of the Hypergame approach. Omega 9:579-594

Berardo R, Lubell M (2016) Understanding what shapes a polycentric governance system. Pub Adm Rev 76:731-751

Black LJ, Andersen DF (2012) Using visual representations as boundary objects to resolve conflict in collaborative model-building approaches. Syst Res Behav Sci 29:194-208

Bryant J (2010) The role of drama Theory in negotiation. In: Kilgour DM, Eden C (eds) Handbook for Group Decision and Negotiation. Springer, Dordrecht, pp 223-245

Bryant JW (2016) Acting strategically using drama theory. CRC Press, Boca Raton

Bryson JM (2004) What to do when stakeholders matter: stakeholder identification and analysis techniques. Public Manag Rev 6:21-53

Bryson JM, Cunningham GL, Lokkesmoe KJ (2002) What to do when stakeholders matter: the case of problem formulation for the african american men project of Hennepin county, Minnesota. Public Adm Rev 62:568-584

Bryson JM (2018) Strategic planning for public and nonprofit organizations: a guide to strengthening and sustaining organizational achievement, 5th edn. Wiley, Hoboken, N.J.

Bryson JM, Ackermann F, Eden C (2016) Discovering collaborative advantage: the contributions of goal categories and visual strategy mapping. Pub Adm Rev 76:912-925

Cargile J (1991) Thought experiments in science and philosophy. Res 54:479-482

Carlile PR (2002) A pragmatic view of knowledge and boundaries: boundary objects in new product development. Organ Sci 13:442-455

Cummings JL, Doh JP (2000) Identifying who matters: mapping key players in multiple environments California. Manag Rev 42: 83-104

de Geus A (1988) Planning as learning. Harvard Business Review March-April:70-74

Eden C (1987) Problem solving or problem finishing? In: Jackson MC, Keys P (eds.) New Directions in Management Science, Gower, Hants, pp97-107

Eden C, Ackermann F (2004) Use of "soft-OR" models by clients - what do they want from them? In: Pidd M (ed) Systems Modelling: Theory and Practice. Wiley, Chichester, pp 146-163 
Eden C, Ackermann F, Bryson J, Richardson G, Andersen D, Finn C (2009) Integrating modes of policy analysis and strategic management practice: requisite elements and dilemmas. J Op Res Soc 60:2-13

Eden C, Ackermann F (1998) Making Strategy: The Journey of Strategic Management. Sage, London

Eden C, Ackermann F (2013) Problem structuring: on the nature of, and reaching agreement about, goals. EURO J Decis Process 1:7-28

Eden C, Ackermann F (2018) Theory into practice, practice to theory: action research in method development. Eur J Oper Res 271:1145-1155

Eden C, Ackermann F, McKiernan P (2019) Stakeholders in strategy: their "invisible" but significant presence. Academy of Management conference, Boston

Elias AA (2019) Strategy development through stakeholder involvement: a New Zealand study. Glob J Flex Syst Manag 20:313-322

Elsaid A, Salem R, Abdul-Kade H (2017) A dynamic stakeholder classification and prioritization based on hybrid rough-fuzzy method. J Softw Eng 11:143-159

Eskerod P, Jepson AL (2013) Project stakeholder management. Gower, London

Eskerod P, Jepsen AL (2016) Project stakeholder management. Routledge, Abingdon, UK

Fang L, Hipel KW, Kilgour DM (1993) Interactive decision MAKING: the graph model for conflict resolution. Wiley, New York

Franco LA (2013) Rethinking soft OR interventions: models as boundary objects. Eur J Oper Res 231:720-733

Freeman RE (1984) Strategic management: a stakeholder perspective. Pitman, Boston

Freeman RE, McVea J (2001) The blackwell handbook of strategic management. Blackwell Publishing, Oxford

Frooman J (1999) Stakeholder influence strategies. Acad Manag Rev 24:191-205

Garavan TN (1995) Stakeholders and strategic human resource development. J Eur Ind Train 19:11-16

Gettleman J (25 January 2015) Meant to keep malaria out, mosquito nets are used to haul fish in. New York Times http://www.nytimes.com/2015/01/25/world/africa/mosquito-nets-for-malaria-spawnnew-epidemic-overfishing.html:

Jepsen AL, Eskerod P (2009) Stakeholder analysis in projects: challenges in using current guidelines in the real world. Int J Project Manage 27:335-343

Lewin K (1951) Field theory in social science: selected theoretical papers. Harper \& Row, New York

Lubell M (2013) Governing institutional complexity: the ecology of games framework. Policy Stud J 41:537-559

March JG, Heath C (1994) A primer on decision making: how decisions happen. Free Press, New York

McElroy B, Mills C (2010) Managing stakeholders. In Turner JR (ed.) Gower handbook of project management (4th Edn.) Routledge, Oxford

Mitchell RK, Agle BR, Wood DJ (1997) Toward a theory of stakeholder identification and salience: defining the principle of who and what really counts. Acad Manag Rev 22:853-886

Narayana SA, Elias AA, Pati RK (2014) Reverse logistics in the pharmaceuticals industry: a systemic analysis. Int J Log Manag 25:379-398

Olander S, Landin A (2005) Evaluation of stakeholder influence in the implementation of construction projects. Int J Project Manage 23:321-328

Park HH, Rethemeyer RK (2014) The politics of connections: assessing the determinants of social structure in policy networks. J Pub Adm Res Theory 24:349-379

Quick KS, Feldman MS (2014) Boundaries as junctures: collaborative boundary work for building efficient resilience. J Pub Admin Res Theory 24:673-695

Richardson G (1991) Feedback thought in social science and systems theory. University of Pennsylvania Press, Philadelphia

Schiffman L, Kanuk L (2009) Consumer behavior. Pearson Education Inc., Upper Saddle River

Winnicott DW (1953) Transitional objects and transitional phenomena: a study of the first not-me possession. Int J Psych-Anal XXXIV Part 2:89-97

Publisher's Note Springer Nature remains neutral with regard to jurisdictional claims in published maps and institutional affiliations. 